\title{
Expression of toll-like receptor 2 (TLR2) in porcine leukocyte subsets and tissues
}

\author{
Belén Álvarez ${ }^{1}$, Concepción Revilla ${ }^{1}$, Nieves DoméNeCH ${ }^{2}$, Carlos PÉREZ ${ }^{1}$, \\ Paloma MARTínEZ ${ }^{1}$, Fernando ALONSO ${ }^{1}$, Angel EZQUERRA ${ }^{1}$, \\ Javier DoMíGUEZ ${ }^{1 *}$ \\ ${ }^{1}$ Dpto. Biotecnología, Instituto Nacional de Investigación y Tecnología Agraria y Alimentaria (INIA),
28040 Madrid, Spain
${ }^{2}$ Unidad de Investigación, CHU Juan Canalejo, 15006 La Coruña, Spain
}

(Received 23 April 2007; accepted 19 October 2007)

\begin{abstract}
Toll-like receptors (TLR) are a group of pattern recognition molecules that play a crucial role in innate immunity. TLR2 recognises a variety of microbial components leading to the development of inflammatory and immune responses. To characterise the expression and functional properties of porcine TLR2 (pTLR2), we have raised a panel of monoclonal antibodies (mAb) against this molecule. Mouse $3 T 3$ cell transfectants expressing pTLR2 were used for immunisation of mice. The specificity of these antibodies was confirmed by their reactivity with $\mathrm{CHO}$ cells transfected with pTLR2 but not with pTLR4 or with non-transfected cells. Using one of these mAbs, named 1H11, pTLR2 was found on cells of the innate immune system, including monocytes, macrophages, and granulocytes, but not on peripheral blood lymphocytes. Staining of tissue sections showed that pTLR2 is also expressed on epithelial cells lining the tracheobronchial and intestinal tracts, bile ducts in the liver and renal tubules, and on the basal layer of the epidermis. This distribution is consistent with a surveillance function at entry sites, allowing for early detection of microbial invasion.
\end{abstract}

toll-like receptor / monoclonal antibody / monocyte / epithelial cell / pig

\section{INTRODUCTION}

Cells of the innate immune system express a range of receptors referred to as patternrecognition receptors (PRRs) that serve to sense microbial infection leading to development of inflammatory and immune responses. These receptors recognise conserved molecular structures, called pathogen-associated molecular patterns (PAMPs), which are shared by large groups of micro-organisms [21].

Toll-like receptors (TLRs) constitute an ancient family of PRRs characterised by an extracellular domain containing multiple leucine-rich repeats (LRRs) and a cytoplasmic domain homologous to that of the interleukin 1

\footnotetext{
*Corresponding author: juncal@inia.es
}

(IL-1) receptor, known as the TIR domain. Up to date 13 TLRs have been identified in mammals, although their expression varies among species [5].

Stimulation of macrophages or mast cells through their TLRs leads to synthesis and secretion of pro-inflammatory cytokines and other mediators, thereby initiating an inflammatory response. Additionally TLR activation of dendritic cells induces the initiation of an adaptive immune response through the upregulation of co-stimulatory molecules [20,31].

TLR2 recognises a variety of microbial components including lipoproteins and lipopeptides from various pathogens, peptidoglycan and lipoteichoic acid from Grampositive bacteria, lipoarabinomannan from 
mycobacteria, and zymosan from yeasts. It is believed that TLR2 associates in heterodimers with TLR1 and TLR6 [31]. Whereas the response to diacylated bacterial lipoproteins requires TLR2 and TLR6, the response to triacylated bacterial lipoproteins depends on TLR2 and TLR1 [32,33]. TLR2 ligands induce maturation of DCs with up-regulation of MHC class II, CD80 and CD86 [18,25] and secretion of IL-12 from monocytes and DC $[6,34]$. Upon ligation TLR2 is rapidly internalised into endosomes. Targeting of antigen to TLR2 may therefore be a useful vaccination strategy for enhancing $\mathrm{CD}^{+} \mathrm{T}$ cell responses by delivering epitopes into the MHC class II pathway [29].

To characterise the expression and functional properties of porcine TLR2, we raised a panel of monoclonal antibodies (mAb) against this molecule. Using one of these mAbs, named 1H11, pTLR2 was found on cells of the innate immune system, including monocytes, macrophages, and granulocytes, but not on peripheral blood lymphocytes. Staining of tissue sections showed that TLR2 is also expressed on epithelial cells lining the tracheobronchial and intestinal tracts, bile ducts in the liver, and renal tubules, and on the basal layer of the epidermis, a distribution consistent with its surveillance function of bacterial invasion.

\section{MATERIALS AND METHODS}

\subsection{Tissues and cells}

Tissue samples for immunohistochemical analyses were collected from three healthy, conventionally reared, 3-month-old Large-White pigs that had been euthanised with azaperone and ketamine.

Blood samples were obtained from six 14- to 20month-old Large-White outbreed pigs. Peripheral blood mononuclear cells (PBMC) were isolated on Percoll (Pharmacia, Uppsala, Sweden) discontinuous gradients after blood sedimentation in Dextran (Pharmacia), as has been previously described [17]. Granulocytes were recovered from the lower Percoll phase after lysis of residual erythrocytes by hypotonic treatment.

Blood monocytes were magnetically isolated using anti-CD172a mAb BA1C11 [2] and the VarioMACS cell sorting technique (Miltenyi Biotec, Bergisch-Gladbach, Germany). Dendritic cells (DC) were derived from monocytes by culturing them in the presence of rpGM-CSF and rpIL-4, as described elsewhere [10]. On day 5, rpTNF$\alpha$ was added to induce their maturation. Alveolar macrophages were collected by bronchoalveolar lavage as described by Carrascosa et al. [9].

Mouse embryo NIH/3T3 cells were obtained from the American type culture collection (ATCC, Manassas, VA) and grown in Dulbecco's modified Eagle's minimal essential medium (DMEM) (BioWhittaker, Verviers, Belgium) supplemented with $30 \mu \mathrm{g} / \mathrm{mL}$ gentamicin, $2 \mathrm{mM}$ L-glutamine and $10 \%$ fetal bovine serum (FBS) (BioWhittaker), at $37^{\circ} \mathrm{C}$ in a humidified $5 \% \mathrm{CO}_{2}$ atmosphere.

The reported experiments have been executed in full compliance with guidelines by the ethical committee of the Institute.

\subsection{Cloning of porcine TLR2 cDNA}

Messenger RNA was extracted from porcine alveolar macrophages using $\mu$ MACS mRNA isolation kit (Miltenyi Biotec). One microgram of poly $\mathrm{A}^{+}$RNA was used to synthesise cDNA and a series of 5' - and 3'-rapid amplification of cDNA ends (RACE) PCR reactions were performed to determine the full-length TLR2 cDNA sequence using the SMART ${ }^{\mathrm{TM}}$ RACE Amplification Kit (BD Biosciences Clontech, CA, USA). TLR2-specific 5' and 3'RACE primers (Tab. I) were designed based on a porcine TLR2 partial coding sequence (CDS) (GenBank accession number AY289531). The PCR products from partial TLR2 cDNAs were cloned into pcDNA3.1/V5-His TOPO vector using a TA cloning kit (Invitrogen, San Diego, CA, USA). The plasmid DNAs were purified using the QIAprep spin miniprep kit (Qiagen, Hilden, Germany) and sequenced with universal oligonucleotides $\mathrm{T} 7$ and $\mathrm{BGH}$.

While we were checking the sequences of our clones, it was published in the databases the first complete CDS of porcine TLR2 (GenBank accession number AB085935). Based on our results and on the new sequence, the primers ST2F and ST2R (Tab. I) were designed for PCR amplification of full-length coding cDNA of pig TLR2. These primers flank the TLR2 translation start and stop codons. cDNA from alveolar macrophages was amplified using BD AdvantageTM 2 PCR Enzyme System as recommended by the manufacturer (BD Biosciences Clontech). Amplification was performed by 5 cycles of $94{ }^{\circ} \mathrm{C}$ for $30 \mathrm{~s}$ and $72{ }^{\circ} \mathrm{C}$ for $3 \mathrm{~min} ; 5$ cycles of $94{ }^{\circ} \mathrm{C}$ for $30 \mathrm{~s}, 70{ }^{\circ} \mathrm{C}$ for $30 \mathrm{~s}$, and $72{ }^{\circ} \mathrm{C}$ for $3 \mathrm{~min}$, and finally 25 cycles of $94{ }^{\circ} \mathrm{C}$ for $30 \mathrm{~s}, 68{ }^{\circ} \mathrm{C}$ for $30 \mathrm{~s}$, and $72{ }^{\circ} \mathrm{C}$ for $3 \mathrm{~min}$. A 
Table I. Primer sequences used in this study.

\begin{tabular}{lccc}
\hline Primer & Sequence & Size (bp) & \\
\hline R4F & TGG TGT CCG TCG TGT GCT GTG CCC TCT TCC TG & - & 3'-RACE PCR \\
R5R & AGC AGC AGG AAG AGG GCA CAG CAC ACG ACG GAC & - & 5'-RACE PCR \\
ST2F & GGA CCA TGC CAT GTG CTT TGT GGA CAG CAT GGG & 2402 & Full-length TLR2 \\
ST2R & AGA CCA GCA TCG GAC CAA GAC TGG CCT TTC & & \\
T2ATGF & GGA CCA TGC CAT GTG CTT TGT GG & 2361 & TLR2-GFP \\
T2CDSGFPR & GGG ACT TGA TCG CAG CTC TCA AAT TT & & \\
\hline
\end{tabular}

band of $2300-2500 \mathrm{bp}$ was purified after agarose gel electrophoresis of PCR-amplified products, and cloned into the pcDNA3.1/V5-His TOPO (Invitrogen). Different clones were sequenced to confirm the fidelity and orientation of inserts. The sequence obtained only differs from those reported by Muneta et al. [26] (accession number AB085935) and Tohno et al. [35] (accession number AB072190) by 3 and 13 nucleotides, respectively, resulting in 2 amino acid differences with the former sequence $(3 \mathrm{R} \rightarrow \mathrm{C}$ and $616 \mathrm{Q} \rightarrow \mathrm{L})$ and 4 with the latter (126 $\mathrm{A} \rightarrow \mathrm{T}, 338 \mathrm{~T} \rightarrow \mathrm{A}, 451 \mathrm{G} \rightarrow \mathrm{S}$, and $633 \mathrm{~L} \rightarrow \mathrm{R}$ ).

\subsection{Construction of eukaryotic expression vector for porcine TLR2}

Based on the complete sequence of porcine TLR2, primers T2ATGF and T2CDSGFPR (Tab. I) were designed to clone the full-length ORF as a fusion protein to GFP by PCR. A 2361-bp product was cloned into pcDNA3.1/CT-GFP-TOPO (Invitrogen) according to the manufacturer's protocol. Several clones of this construct (pTLR2-GFP) were sequenced to confirm the orientation and the integrity of the inserts.

\subsection{Transient expression of TLR2-GFP construct and analysis by flow cytometry}

$\mathrm{NIH} / 3 \mathrm{~T} 3$ or $\mathrm{CHO}$ cells were transfected with plasmid pTLR2-GFP encoding full-length TLR2GFP fusion protein by using the LipofectAMINE PLUS reagent (Invitrogen) according to the manufacturer's instructions. Briefly, the day prior to transfection, cells were seeded into 6-well plates $\left(3 \times 10^{5}\right.$ cells/w) and grown in DMEM supplemented with $30 \mu \mathrm{g} / \mathrm{mL}$ gentamicin, $2 \mathrm{mM} \mathrm{L}$ glutamine, and 10\% FBS. Immediately before transfection, cells were rinsed with medium without serum nor antibiotic (transfection medium, TM). For each well, $1 \mu \mathrm{g}$ of plasmid DNA plus $6 \mu \mathrm{L}$ of PLUS reagent were mixed, diluted with $500 \mu \mathrm{L}$ of TM and incubated for $15 \mathrm{~min}$ at room temperature. Then $4 \mu \mathrm{L}$ of Lipofectamine were mixed with
$500 \mu \mathrm{L}$ of $\mathrm{TM}$ and added to the former mixture. After 15 min incubation, the DNA/LipofectAMINE PLUS complexes were added to the cells. Cells were incubated for $3 \mathrm{~h}$ at $37{ }^{\circ} \mathrm{C}$ in $5 \% \mathrm{CO}_{2}$, and then $1 \mathrm{~mL}$ of fresh growth medium was added. Cells were harvested at $24 \mathrm{~h}$ post-transfection and directly analysed on a FACScalibur flow cytometer. Cells transfected with a plasmid encoding the full-length pTLR4-GFP fusion protein [1] or non-transfected cells were used as negative control.

\subsection{Monoclonal antibody production}

To raise $\mathrm{mAb}$ against porcine TLR2 10-week-old BALB/c mice were i.v. immunised with pTLR2-GFP-transfected NIH/3T3 mouse cells $\left(2 \times 10^{6}\right.$ cells $/ 0.1 \mathrm{~mL}$ of sterile PBS $)$, and boosted on days 15 and 30 with the same amount of cells. Serum from immunised mice was collected 7-10 days after each boost, and the presence of specific Abs was tested in flow cytometry using pTLR2-GFP-transfected CHO cells; as a negative control, non-transfected $\mathrm{CHO}$ cells were used. Selected mice were boosted i.v. with $2 \times 10^{6}$ cells in $0.1 \mathrm{~mL}$ sterile PBS four days before fusion of spleen lymphocytes with the SP2/0 murine plasmacytoma, using polyethylene glycol 4000 (Merck, West Point, PA, USA) according to current protocols [23].

Class and subclass of mAbs were determined by immunodot with a mouse monoclonal antibody isotyping test kit from Serotec (Oxford, UK). MAb $1 \mathrm{H} 11$ is isotype $\mathrm{IgG}_{1} \kappa$.

MAbs to porcine CD3 (BB23-8E, $\operatorname{IgG}_{2 \mathrm{~b}}$ ), CD4 (74-12-4, $\left.\mathrm{IgG}_{2 \mathrm{~b}}\right)$, and $\mathrm{CD} 8 \alpha\left(76-2-11, \mathrm{IgG}_{2 \mathrm{a}}\right)$ were kindly provided by M. Pescovitz (Indiana University, USA); mAb to $\mathrm{CD} 16\left(\mathrm{G} 7, \mathrm{IgG}_{1}\right)$ was a gift from Y.B. Kim (Finch University of Health Sciences, IL, USA); mAbs to porcine CD172a $\left(\mathrm{BA} 1 \mathrm{C} 11, \mathrm{IgG}_{1}\right)$ and CD45RA $\left(3 \mathrm{C} 3 / 9, \quad \mathrm{IgG}_{1}\right)$ were produced in our laboratory; mAbs to $\mathrm{CD} 8 \beta$ $\left(\mathrm{PG} 164 \mathrm{~A}, \mathrm{IgG}_{2 \mathrm{a}}\right.$ ) and TCR $\gamma \delta\left(\mathrm{PGBL} 22 \mathrm{~A}, \mathrm{IgG}_{1}\right.$ ) were purchased from VMRD (Pullman, WA, USA) 
and $\mathrm{mAb}$ to $\mathrm{CD} 21$ (B-Ly4; $\mathrm{IgG}_{1}$ ) was obtained from BD Pharmingen (CA, USA).

For multi-colour immunofluorescence assays, mAbs were purified by affinity chromatography on Protein A-Sepharose CL4B (Pharmacia), and labelled with either biotin (Sigma, Saint Louis, MO, USA), Alexa Fluor 488 or Alexa Fluor 633 (Molecular Probes, Eugene, OR, USA) following the manufacturer's protocol.

\subsection{Flow cytometry}

For single-colour staining, cells $\left(5 \times 10^{5}\right)$ were incubated with $75 \mu \mathrm{L}$ hybridoma supernatant for $30 \mathrm{~min}$ at $4{ }^{\circ} \mathrm{C}$. After two washes in PBS containing $0.1 \%$ BSA and $0.01 \%$ sodium azide (washing buffer), cells were incubated with FITC or phycoerythrin (PE)-conjugated rabbit $\mathrm{F}\left(\mathrm{ab}^{\prime}\right)_{2}$ antimouse Ig (Dako, Glostrup, Denmark). Then, they were washed and fixed in $0.1 \%$ formaldehyde prior to analysis on a FACScalibur cytometer (Becton Dickinson, USA). Irrelevant isotype-matched mAbs were used as negative controls.

For two-colour staining, after incubation with FITC-conjugated rabbit $\left.\mathrm{F}(\mathrm{ab})_{2}\right)_{2}$ anti-mouse Ig, cells were washed and free binding sites blocked with 5\% normal mouse serum for $15 \mathrm{~min}$. Then, biotinylated mAbs were added and detected with streptavidin-PE (BD Pharmingen). Subsequently, cells were washed and fixed in $0.1 \%$ formaldehyde prior to analysis on the cytometer. Irrelevant isotype-matched mAbs, unlabelled or labelled with biotin were used as negative controls.

For three-colour staining, cells were incubated with 1H11 hybridoma supernatant and Alexa 488labelled anti-CD4 mAb for $30 \mathrm{~min}$ at $4{ }^{\circ} \mathrm{C}$. After washing, cells were incubated for $30 \mathrm{~min}$ at $4{ }^{\circ} \mathrm{C}$ with PE-conjugated goat $\mathrm{F}\left(\mathrm{ab}^{\prime}\right)_{2}$ anti-mouse IgG1 (Southern Biotech, AL, USA). Cells were washed and blocked with 5\% normal mouse serum, and then Alexa 633-labelled anti-CD172a mAb was added. Cells were washed twice and fixed in $0.1 \%$ formaldehyde prior to analysis in the cytometer. Irrelevant isotype-matched mAbs, unlabelled or labelled with the different fluorochromes, were used as negative controls.

\subsection{Immunoprecipitation analysis}

Non-transfected or pTLR2-GFP-transfected CHO cells $\left(3 \times 10^{6}\right)$ were washed twice with PBS and solubilised in $0.3 \mathrm{~mL}$ of lysis buffer (50 mM Tris- $\mathrm{HCl} \mathrm{pH} 7.4,150 \mathrm{mM} \mathrm{NaCl}, 5 \mathrm{mM}$ EDTA, $1 \%$ NP40, $10 \mu \mathrm{g} / \mathrm{mL}$ aprotinin and $1 \mathrm{mM}$ phenylmethylsulfonylfluoride) for $1 \mathrm{~h}$ at $4{ }^{\circ} \mathrm{C}$. After centrifugation at $12000 \times g$ for $30 \mathrm{~min}$, the supernatants were precleared with $25 \mu \mathrm{L}$ of a $25 \%(\mathrm{v} / \mathrm{v})$ suspension of protein G-Sepharose (Pharmacia) in lysis buffer, and then subjected to immunoprecipitation with mAb $1 \mathrm{H} 11$ or an irrelevant mAb. Hybridoma supernatant $(300 \mu \mathrm{L})$ was added to $0.1 \mathrm{~mL}$ of lysate and incubated for $2 \mathrm{~h}$ at room temperature. Then, $40 \mu \mathrm{L}$ of $25 \%$ (v/v) suspension of protein G-Sepharose were added and incubated for $1 \mathrm{~h}$ with gentle mixing. Beads were washed three times with lysis buffer and boiled in electrophoresis sample buffer $(0.062 \mathrm{M}$ Tris- $\mathrm{HCl} \mathrm{pH}$ 6.8, 2\% SDS, $10 \%$ glycerol, $0.7 \mathrm{M}$ 2-mercaptoethanol, $0.001 \%$ bromophenol blue). Bound proteins were resolved by $7.5 \%$ SDS-PAGE, transferred to nitrocellulose and analysed by Western blotting with an anti-GFP mAb conjugated to horseradish peroxidase (HRP) (Miltenyi Biotec). Peroxidase activity was visualised with the ECL detection assay following the recommendations of the manufacturer (Amersham, Uppsala, Sweden).

\subsection{Immunohistochemical analyses}

Part of the tissue samples were snap frozen in isopentane/liquid nitrogen and stored at $-80{ }^{\circ} \mathrm{C}$. Frozen sections were cut at $6 \mu \mathrm{m}$ thick, mounted on poly-L-lysine coated glass slides, and air-dried overnight at room temperature. Slides were then fixed for $10 \mathrm{~min}$ in acetone and stained according to previously described protocols [13].

Another part of the tissues were fixed in neutral buffered $10 \%$ formalin for $12 \mathrm{~h}$, and embedded in paraffin wax. Serial $4 \mu \mathrm{m}$ sections were cut, placed on silane coated slides, and allowed to dry at room temperature. Slides were dewaxed in xylene and rehydrated through graded alcohols to distilled water. Slides were then subjected to heat-mediated antigen retrieval treatment in $10 \mathrm{mM}$ Tris, $1 \mathrm{mM}$ EDTA $\mathrm{pH}$ 9.0, and stained as previously described [13].

\subsection{Effect of anti-TLR 2 antibody in TNF- $\alpha$ production}

To induce TNF- $\alpha$ production through TLR2, PBMC were cultured in 12-well tissue culture plates at concentrations of $5 \times 10^{6}$ cells/well with $\mathrm{Pam}_{3} \mathrm{CysSer}(\mathrm{Lys})_{4}$ (hereafter $\mathrm{P}_{3} \mathrm{CSK}_{4}$ ) $(100 \mathrm{ng} / \mathrm{mL})$ or Malp-2 $(1.3 \mathrm{ng} / \mathrm{mL}$ ) (both from Alexis Biochemicals, Lausen, Switzerland) for $24 \mathrm{~h}$ at $37{ }^{\circ} \mathrm{C}$. Concentrations of TNF- $\alpha$ in supernatants were measured by ELISA (BioSource, CA, USA). Blocking of the PBMC activation was attempted 

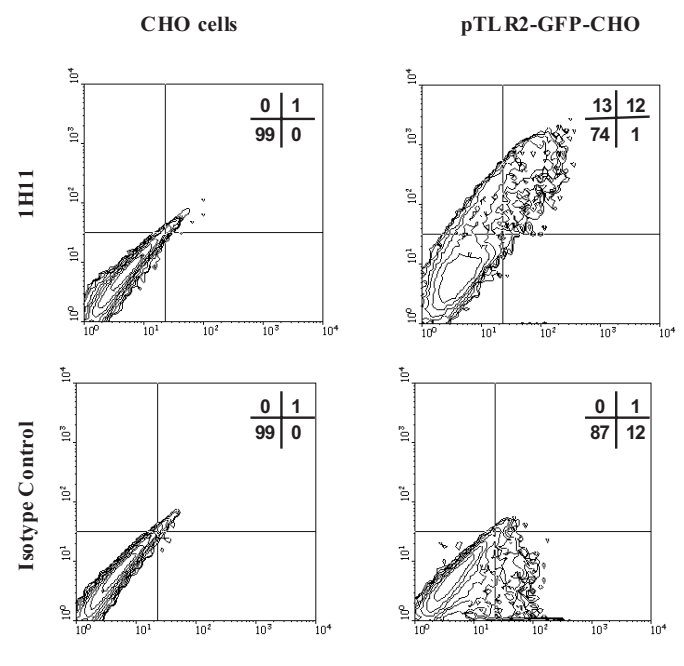

GFP

by incubating cells with mAb $1 \mathrm{H} 11(50 \mu \mathrm{g} / \mathrm{mL})$ or an isotype-matched control antibody, for $30 \mathrm{~min}$ at $37^{\circ} \mathrm{C}$ prior to the addition of the stimuli.

Additionally, the agonistic activity of mAb $1 \mathrm{H} 11$ on TNF- $\alpha$ production was tested by incubating PBMC with this antibody or an isotype-matched control antibody, cross-linked or not with rabbit anti-mouse Ig (Dako, Glostrup, Denmark), for $24 \mathrm{~h}$.

\section{RESULTS}

\subsection{MAb 1H11 specifically recognises porcine TLR2 on transfected cells}

To generate anti-porcine TLR2 mAbs, TLR2 cDNA was amplified and cloned into pcDNA3.1/CT-GFP-TOPO to obtain a GFPtagged version of the porcine TLR2, that was then used to transfect mouse NIH/3T3 cells. These cells were used for mice immunisation. The specificity of mAbs obtained was checked by flow cytometry. MAb $1 \mathrm{H} 11$ reacted with CHO cells transfected with the pTLR2-GFP construct, as shown by the co-expression of GFP fluorescence and 1H11 labelling, but not with CHO cells transfected with a pTLR4GFP construct or with non-transfected cells (Fig. 1). Moreover, when lysates from pTLR2GFP-tranfected CHO cells were immunoprecipitated with mAb $1 \mathrm{H} 11$ and subsequently analysed by Western blotting with an HRPconjugated anti-GFP mAb, a specific band of $115 \mathrm{kDa}$, the expected size for the TLR2-GFP fusion protein, was clearly detected (Fig. 2).
pTLR4-GFP-CHO
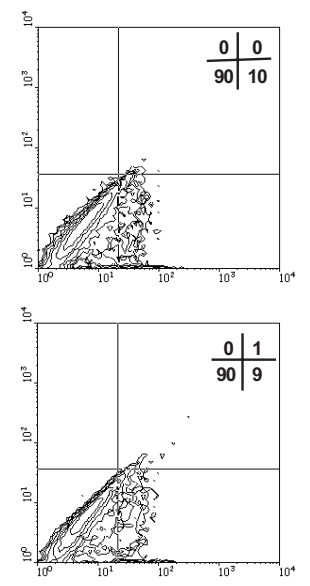

Figure 1. $\mathrm{MAb} 1 \mathrm{H} 11$ specifically recognises porcine TLR2. CHO cells transfected with the pTLR2-GFP or pTLR4-GFP constructs were stained with $\mathrm{mAb}$ $1 \mathrm{H} 11$ or an irrelevant isotype-matched antibody followed by PE-rabbit $\mathrm{F}\left(\mathrm{ab}^{\prime}\right)_{2}$ antimouse Igs and analysed by flow cytometry. A control staining of non-transfected $\mathrm{CHO}$ cells is also shown.

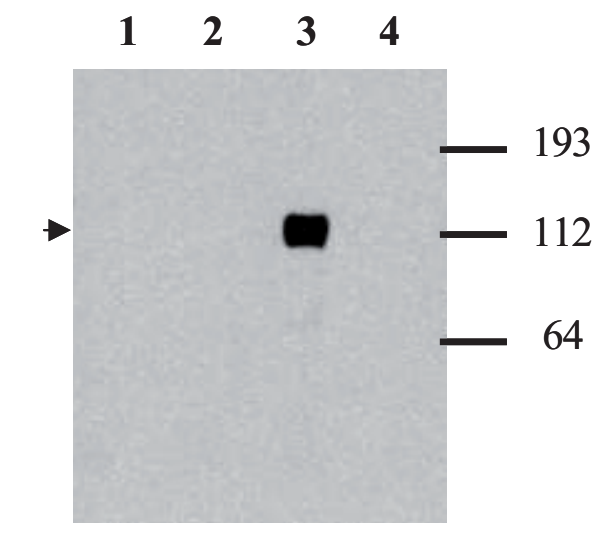

Figure 2. Immunoprecipitation of pTLR2 with $\mathrm{mAb} 1 \mathrm{H} 11$. Cells lysates $\left(3 \times 10^{6}\right.$ cells $)$ were subjected to immunoprecipitation with mAb $1 \mathrm{H} 11$ (1 and 3) or an irrelevant mAb (2 and 4). Bound proteins were resolved by $7.5 \%$ SDS-PAGE under reducing conditions and analyzed by Western blotting with an HRP-conjugated anti-GFP mAb. Lane 1 and 2: non-transfected CHO cells, lane 3 and 4: CHO cells transfected with pTLR2-GFP. Arrowhead show specific band corresponding to the full TLR2 fused to GFP (115 kDa). Numbers on the right indicate the position of MW markers.

These results confirm the specificity of this antibody for porcine TLR2.

\subsection{Distribution of TLR2 in leukocyte subsets}

The reactivity of mAb $1 \mathrm{H} 11$ was next analysed by flow cytometry on different blood cell 


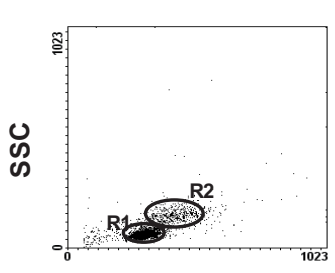

FSC

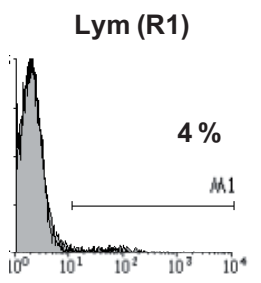

Immature DC (day 5)

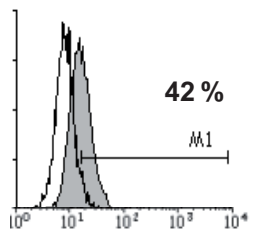

mn (R2)

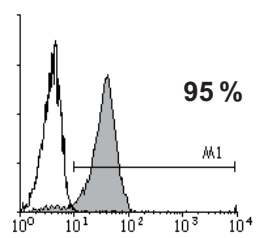

PMN

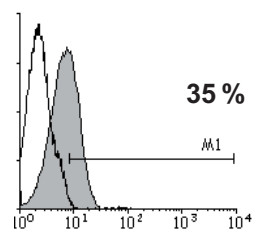

МФ

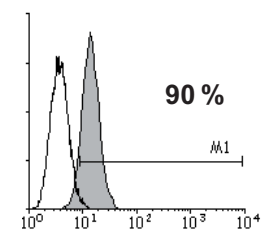

Mature DC (day 7)

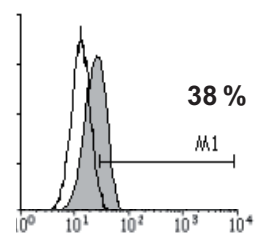

Figure 3. Porcine TLR2 is expressed on cells of the innate immune system. Staining of lymphocytes (Lym), monocytes (mn), granulocytes (PMN), alveolar macrophages (M $\Phi)$, immature DC (day 5) and mature DC (day 7). Cells were stained with mAb $1 \mathrm{H} 11$ followed by FITC-rabbit F(ab')2 anti mouse Ig. An irrelevant isotype matched $\mathrm{mAb}$ was used as negative control (open histogram). Lymphocytes (R1) and monocytes (R2) were gated according their forward (FSC) and side scatter (SSC) profiles. Results are representative of three independent experiments.

populations. TLR2 was detected at high levels on a subset of peripheral blood mononuclear cells, which, accordingly to their FSC and SSC characteristics, corresponded to monocytes. It was also detected, although at lower levels, on the majority of granulocytes. Lymphocytes were negative. Alveolar macrophages also stained positive but with lower intensity than monocytes. Differentiation of monocytes into DCs in the presence of GM-CSF and IL-4, resulted in down-modulation of TLR2 expression (Fig. 3).

The distribution of porcine TLR2 on PBMC was further examined by two-colour flow cytometry (Fig. 4). Porcine TLR2 antigen was expressed on most of CD172a ${ }^{+}$, CD $16^{\text {hi }}$ monocytes. No significant expression was detected on the surface of $\mathrm{T}$ cells or their subsets as defined by the expression of CD3, CD4 ${ }^{+}$, $\mathrm{CD} 8 \alpha^{+}, \mathrm{CD} 8 \beta^{+}$, or $\gamma \delta$ TCR markers. NK and $\mathrm{B}$ cells, identified as CD16 ${ }^{\mathrm{lo}}$ and $\mathrm{CD} 21^{+}$cells respectively, were also negative.

Within the TLR2 ${ }^{+}$CD $172 \mathrm{a}^{+}$cells, a small population expressing low levels of CD172a was identified. Since plasmacytoid dendritic cells (pDC) have been shown to express low levels of CD172a, we carried out threecolour flow cytometric analyses using a CD4/CD172a/TLR2 combination, to investigate whether these cells corresponded to this lineage. As shown in Figure 5, these cells did not express CD4 and therefore did not fit the phenotype described for pDC [30].

\subsection{TLR2 is expressed at portals of pathogen entry}

The distribution of TLR2 in non-lymphoid tissues was analysed by immunohistochemistry on frozen sections (Fig. 6). In the lung, epithelial cells lining tracheobronchial airways were strongly stained, whereas alveolar macrophages were barely detectable. In the small intestine, epithelial cells of villi showed a weak staining that appeared to be predominantly intracellular, whereas goblet cells were negative. The lamina propria was mainly negative. TLR2 expression was also observed in the epithelial cells of renal tubules and in bile ducts within the liver but not in hepatocytes. In the skin, mAb 1H11 strongly labelled the basal layer of the epidermis; positive cells were also occasionally seen in dermis. A similar 


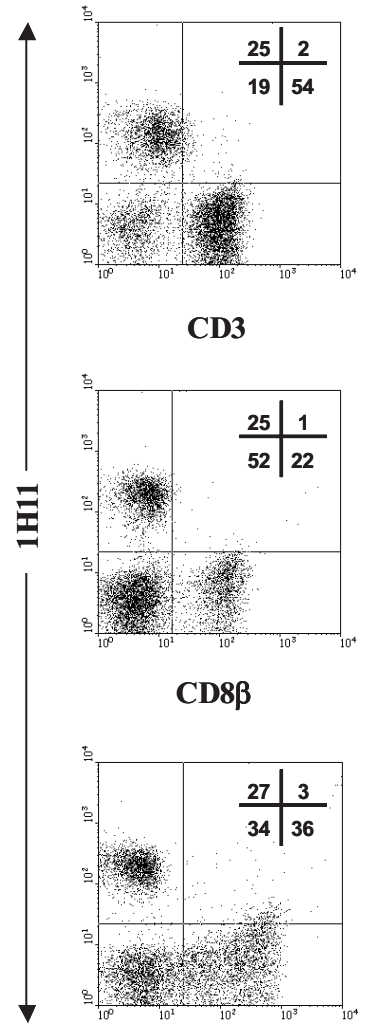

CD45RA

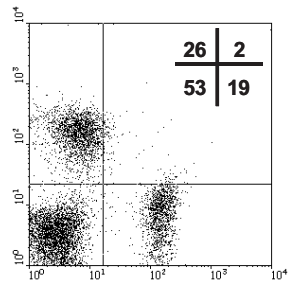

CD4

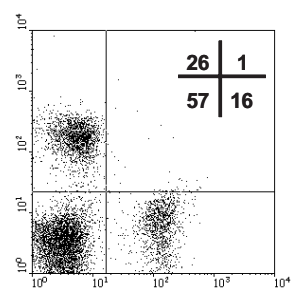

TCR $\gamma \delta$

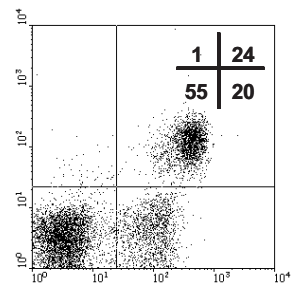

CD16

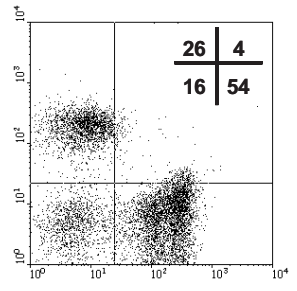

$\mathrm{CD} 8 \alpha$

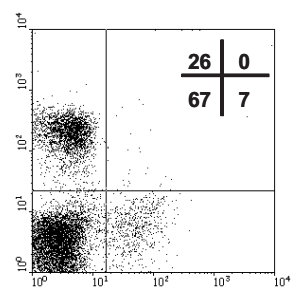

CD21

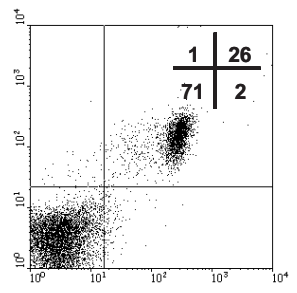

CD172a

Figure 4. Two-colour flow cytometric analysis of TLR2 expression in PBMC subsets. PBMC were doublestained with anti-CD3, anti-CD4, anti-CD8 $\alpha$, anti-CD8 $\beta$, anti-TCR $\gamma \delta$, anti-CD21, anti-CD45RA, anti$\mathrm{CD} 16$ or anti-CD172a mAbs, and rabbit $\mathrm{F}(\mathrm{ab})_{2}$ anti-mouse Ig FITC ( $x$-axis), followed by biotin-conjugated $1 \mathrm{H} 11$ and streptavidin-PE ( $y$-axis). Isotype-matched irrelevant mAbs, unlabelled or biotin-labelled were used as negative controls. Thirty thousand events were acquired. The data shown are from a representative experiment out of four performed with cells from different donors.

staining pattern was observed on formalinfixed paraffin-embedded skin sections that have been subjected to heat-mediated antigen retrieval treatment (Fig. 6F).

\subsection{Effect of mAb $1 \mathrm{H} 11$ on TNF- $\alpha$ production by $\mathrm{PBMC}$ in response to lipopeptides}

Lipopeptides are known to activate monocytes/macrophages through a TLR2dependent pathway leading to the secretion of significant levels of TNF- $\alpha$. To investigate whether mAb $1 \mathrm{H} 11$ was able to interfere TLR2-mediated cell activation, we treated PBMC with this $\mathrm{mAb}$ before the addition of $\mathrm{P}_{3} \mathrm{CSK}_{4}$, a ligand for TLR1/TLR2 heterodimer, or Malp-2, that binds to TLR2/TLR6 heterodimer, and measured the production of TNF- $\alpha$. As shown (Fig. 7), mAb 1H11 did not block the production of TNF- $\alpha$ triggered by $\mathrm{P}_{3} \mathrm{CSK}_{4}$ or Malp-2. This mAb also failed to induce $\mathrm{TNF}-\alpha$ production, even after cross-linking with an anti-mouse Ig antibody (data not shown).

\section{DISCUSSION}

Invasion of host tissues by microbial pathogens causes the activation of first-line defense mechanisms. TLRs are a family of 

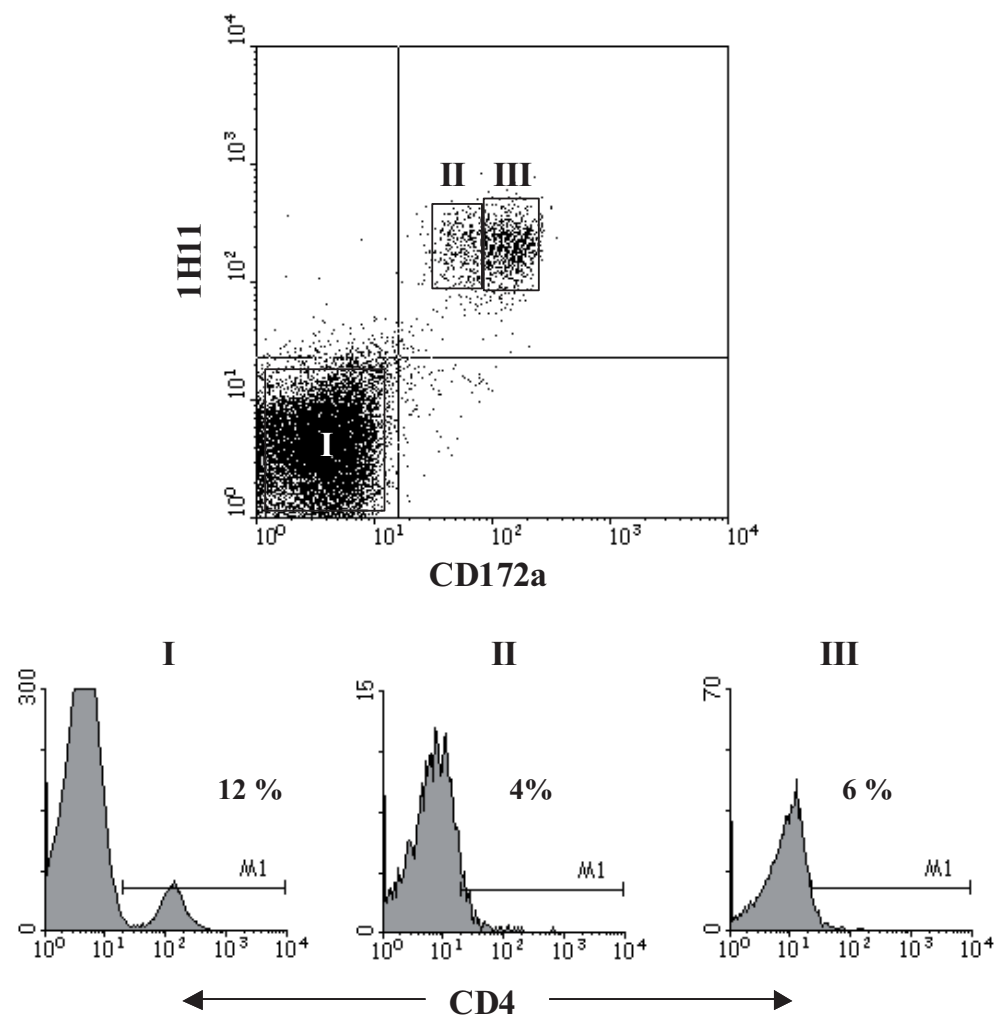

Figure 5. CD4 expression in CD172a $\mathrm{a}^{-} 1 \mathrm{H} 11^{-}$(I), CD172a $\mathrm{a}^{\text {lo }} 1 \mathrm{H} 11^{+}$(II), and CD172a $\mathrm{a}^{\text {hi }} 1 \mathrm{H} 11^{+}$(III) cells assessed by three-colour immunofluorescence. Cells were stained, as described in Materials and Methods, with anti-CD4 labelled with Alexa 488 and $\mathrm{mAb} 1 \mathrm{H} 11$ followed by PE-conjugated goat F(ab') 2 anti-mouse IgG1, and then with Alexa 633-labelled anti-CD172a. Isotype-matched irrelevant mAbs, unlabelled, labelled with Alexa 488 or Alexa 633 were used as negative controls. One hundred thousand events were acquired. Data from one representative out of four independent experiments are shown.

pattern-recognition receptors that detect conserved molecular products of micro-organisms and are involved in the activation and regulation of inflammatory and immune responses. Of the TLRs so far identified, TLR2 plays a major role against infections by Gram-positive bacteria, mycobacteria, and yeasts, binding a wide variety of microbial products such as peptidoglycan, lipoteichoic acid, lipoproteins, lipoarabinomannan, and zymosan. Upon activation by PAMPs, TLR2 predominantly signals to NF- $\kappa \mathrm{B}$, which induces the transcription of an array of genes encoding cytokines and other molecules involved in the initiation of host innate and adaptive immune responses [31].
In this report we describe the characterisation of a mAb to porcine TLR2 and analyse the pattern of expression of this receptor in different leukocyte subsets and tissues to investigate how it can contribute to anti-microbial immune responses. The TLR 2 specificity of this $\mathrm{mAb}$ was determined by its reactivity with CHO transfectants expressing the pTLR2 but not the pTLR4 nor with non-transfected cells. To our knowledge, this is the first report describing the development and characterisation of mAbs against porcine TLR2.

In general, the distribution of TLR2 on porcine leukocyte populations is similar to that reported in humans, being predominantly expressed on myelomonocytic cells such as 

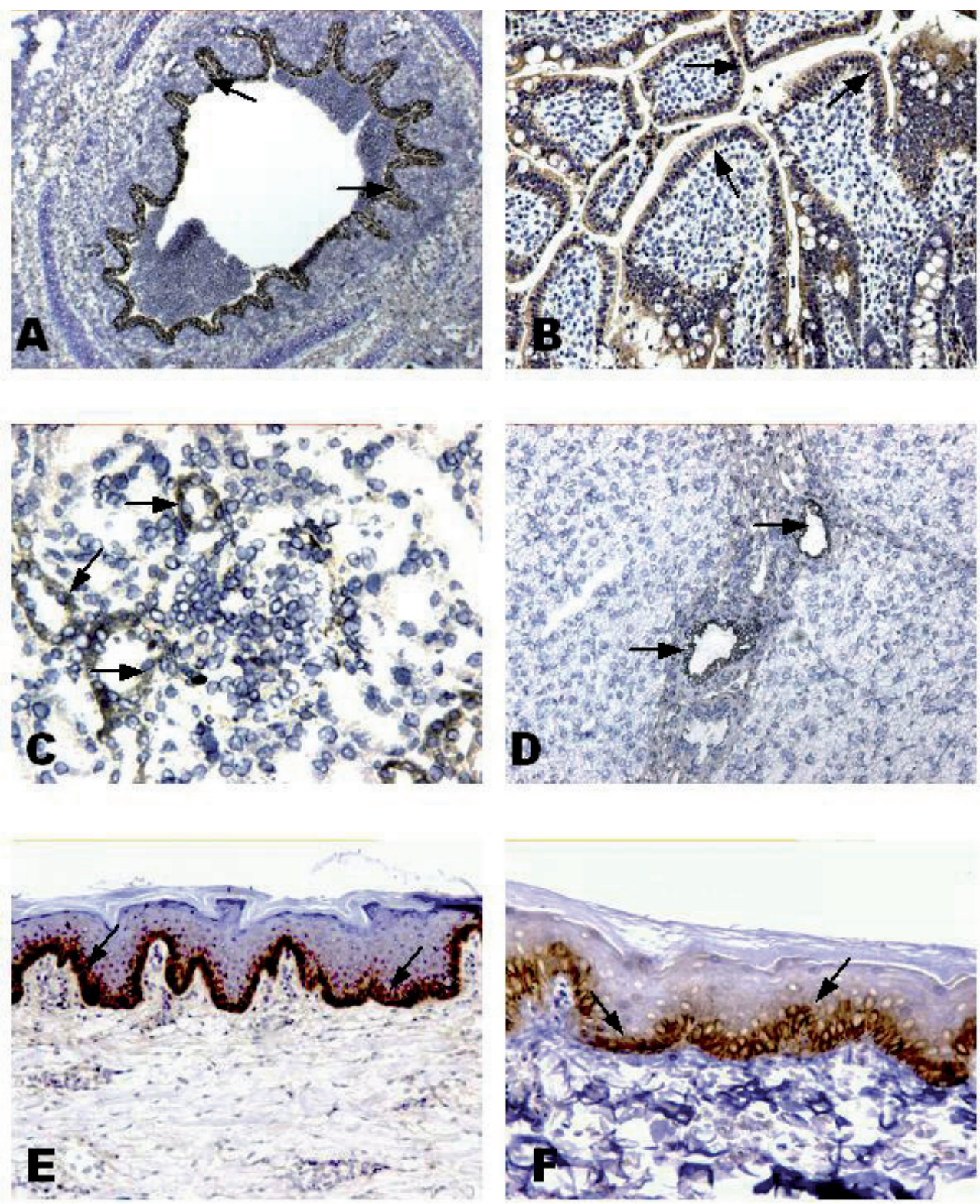

Figure 6. Immunohistochemical staining of frozen sections (A-E) and formalin-fixed, paraffin-embedded sections (F) of porcine tissues with anti-TLR2 mAb 1H11 using the immunoperoxidase method. (A) Lung: Bronchial epithelial cells stain strongly positive. (B) Jejunum: Positive staining of enterocytes. (C) Kidney: TLR2 expression in the epithelium of some renal tubules. (D) Liver: Positive staining of bile ducts. (E, F) Skin: Strong expression of TLR2 in cells of the basal layer of the epidermis. Representative areas of positive staining are indicated by arrows. Original magnifications: $(A) \times 40,(\mathbf{B}, \mathbf{D}$, and $\mathbf{E}) \times 100,(\mathbf{C}$ and $\mathbf{F}) \times 200$. Results are representative of three independent experiments with different donors. 


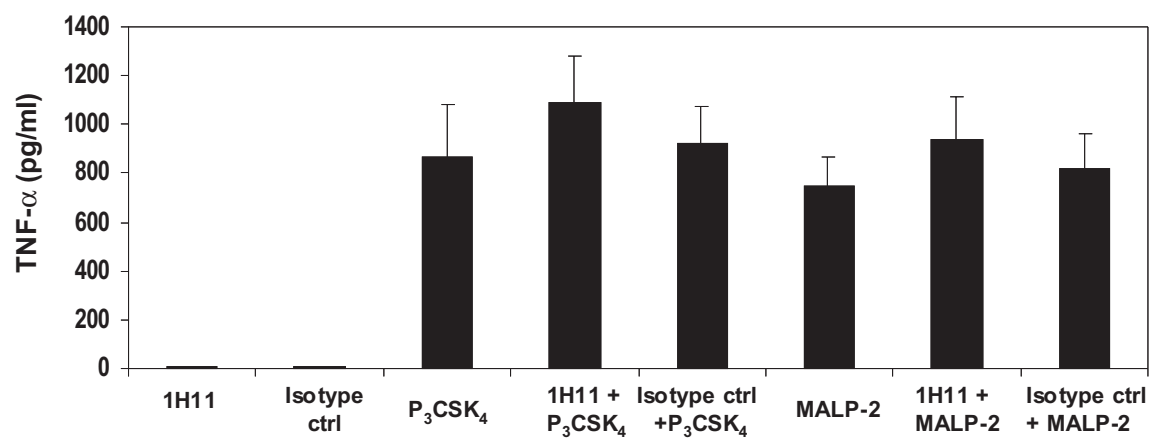

Figure 7. Effect of mAb $1 \mathrm{H} 11$ on TNF- $\alpha$ secretion by PBMC in response to $\mathrm{P}_{3} \mathrm{CSK}_{4}$ and Malp-2. Cells were preincubated with anti-TLR2 $\mathrm{mAb} 1 \mathrm{H} 11(50 \mu \mathrm{g} / \mathrm{mL})$ or an isotype-matched control antibody $(50 \mu \mathrm{g} / \mathrm{mL})$ for $30 \mathrm{~min}$ and then stimulated with $\mathrm{P}_{3} \mathrm{CSK}_{4}(100 \mathrm{ng} / \mathrm{mL})$ or Malp-2 $(1.3 \mathrm{ng} / \mathrm{mL})$ for $24 \mathrm{~h}$. TNF- $\alpha$ level in culture supernatants was determined by ELISA. Data are expressed as the mean \pm SEM of triplicates of one representative out of three experiments performed.

monocytes, macrophages, and neutrophils [15, $27,28,38]$. Like in humans, swine neutrophils express relatively low levels of cell surface TLR2, whereas monocytes express it at high levels [28]. Likewise, differentiation of monocytes into immature DCs by the addition of GM-CSF and IL-4 results in the progressive loss of this receptor $[29,38]$.

Although TLR2 protein has been detected intracellularly in non-stimulated human $\mathrm{T}$ cells [24], none or very few $\mathrm{T}$ cells express TLR2 on the cell surface when they have not been activated [3, 11, 24]. We have not detected expression of TLR2 on the surface of porcine blood T, B, or NK cells. Nevertheless, Tohno et al. [36] have reported a strong expression of TLR 2 in a considerable proportion of $\mathrm{T}$ lymphocytes in porcine Peyer patches and mesenteric lymph nodes (MLNs). They also detected a weak expression on some CD21 ${ }^{+}$ $\mathrm{B}$ cells. This apparent discrepancy may be due to differences in the affinity of the antibodies used (a polyclonal antiserum in their study), differences in the state of activation of cells, or to the different lymphoid compartments analysed (peripheral blood vs lymphoid organs). Indeed, these authors found a stronger TLR2 expression in gut-associated lymphoid tissues (GALT) than in other lymphoid tissues, such as spleen or thymus.

The skin and mucosal surfaces are the most important routes of entry of micro-organisms into the host. In addition to cells of the innate immune system, we have found expression of TLR2 on epithelial cells of the skin, renal tubules, and respiratory and intestinal tracts. These cells provide the first line of defense against invading pathogens. Besides functioning as a mechanical barrier, they produce, in response to microbial products, a variety of cytokines, chemokines and antimicrobial peptides that trigger the activation of tissueresident innate cells and the recruitment of leukocytes to the sites of infection $[19,20,22]$. Constitutive expression of TLR2 has also been reported in epithelial cells of the proximal and distal renal tubules in mouse and in human tracheobronchial epithelial cells and alveolar epithelial type II cells [12, 14, 19, 39]. In the human skin, TLR2 is expressed throughout the epidermis, but shows an increased expression in basal keratinocytes [4], like we have seen in pigs.

Our results show that in skin and bronchial epithelial cells TLR2 expression was relatively strong, whereas enterocytes appeared weakly stained. Previous studies by Tohno et al. [36, 37] reported a low expression of TLR 2 mRNA by real-time quantitative PCR in the porcine gut, but failed to detect TLR2 at the protein level except in the $M$ cells which cover the mucosa-associated lymphoid tissue. Nevertheless, a low expression of TLR2 has been reported in human intestinal epithelial cells (IECs) in vitro and in vivo $[7,8,16]$. This low expression may be a way of minimising 
lumenal recognition of molecular patterns of commensal flora in the healthy intestine [8]. In IECs, TLR2 and TLR4 have been shown to traffic from apical to cytoplasmic compartments in response to specific bacterial ligands, and might play important roles in conveying bacterial products to the underlying immune and inflammatory cell populations of the lamina propria [8].

Targeting Ag to TLR2 has been proposed as a useful strategy to enhance vaccine immunogenicity [29]. Signalling through TLR2 leads to maturation of APCs (DCs) resulting in the up-regulation of MHC class II and costimulatory molecules (CD80, CD86) [18]. It also induces local inflammation with the consequent increase in the number of these APCs at the inoculation site. Besides, TLR2 is an endocytic receptor that delivers ligands into the MHC class II presentation pathway. Although $\mathrm{mAb} 1 \mathrm{H} 11$ failed to induce the production of TNF- $\alpha$ by monocytes, that we analysed as a measure of activation, it may still be useful for the development of Ab-based vaccines by improving the uptake of antigen by APCs. Further studies will determine the ability of this $\mathrm{mAb}$ to deliver antigens into MHC class I and MHC class II pathways for T cell priming.

Acknowledgements. This work was supported by grants AGL2004-4074 and CSD2006-0007 from the Spanish Ministry of Education and Science. CR was recipient of a RyC contract of the Spanish Ministry of Education and Science.

\section{REFERENCES}

[1] Alvarez B., Revilla C., Chamorro S., Lopez-Fraga M., Alonso F., Domínguez J., Ezquerra A., Molecular cloning, characterisation and tissue expression of porcine toll-like receptor 4, Dev. Comp. Immunol. (2006) 30:345-355.

[2] Alvarez B., Gómez N., Garrido J., Yerle M., Revilla C., Chamorro S., Alonso F., Domínguez J., Ezquerra A., Molecular cloning, characterization and expression of porcine immunoreceptor SIRP-alpha, Dev. Comp. Immunol. (2007) 31:307-318.

[3] Babu S., Blauvelt C.P., Kumaraswami V., Nutman T.B., Cutting edge: diminished T cell TLR expression and function modulates the immune response in human filarial infection, J. Immunol. (2006) 176:3885-3889.

[4] Baker B.S., Ovigne J.M., Powles A.V., Corcoran S., Fry L., Normal keratinocytes express toll-like receptors (TLRs) 1, 2, and 5: modulation of TLR expression in chronic plaque psoriasis, Br. J. Dermatol. (2003) 148:670-679.
[5] Beutler B., Jiang Z., Georgel P., Crozat K., Croker B., Rutschmann S., Du X., Hoebe K., Genetic analysis of host resistance: toll-like receptor signaling and immunity at large, Annu. Rev. Immunol. (2006) 24:353-389.

[6] Brightbill H.D., Libraty D.H., Krutzik S.R., Yang R.B., Belisle J.T., Bleharski J.R., Maitland M., Norgard M.V., Plevy S.E., Smale S.T., Brennan P.J., Bloom B.R., Godowski P.J., Modlin R.L., Host defense mechanisms triggered by microbial lipoproteins through toll-like receptors, Science (1999) 285:732736.

[7] Cario E., Podolsky D.K., Differential alteration in intestinal epithelial cell expression of toll-like receptor 3 (TLR3) and TLR4 in inflammatory bowel disease, Infect. Immun. (2000) 68:7010-7017.

[8] Cario E., Brown D., McKee M., Lynch-Devaney K., Gerken G., Podolsky D.K., Commensal-associated molecular patterns induce selective Toll-like receptor trafficking from apical membrane to cytoplasmic compartments in polarised intestinal epithelium, Am. J. Pathol. (2002) 160:165-173.

[9] Carrascosa A.L., Santaren J., Viñuela E., Production and titration of African swine fever virus in porcine alveolar macrophages, J. Virol. Methods (1982) 3:303-310.

[10] Chamorro S., Revilla C., Gómez N., Alvarez B., Alonso F., Ezquerra A., Domínguez J., In vitro differentiation of porcine blood CD163- and CD163+ monocytes into functional dendritic cells, Immunobiology (2004) 209:57-65.

[11] Dasari P., Nicholson I.C., Hodge G., Dandie G.W., Zola H., Expression of toll-like receptors on B lymphocytes, Cell Immunol. (2005) 236:140-145.

[12] Diamond G., Legarda D., Ryan L.K., The innate immune response of the respiratory epithelium, Immunol. Rev. (2000) 173:27-38.

[13] Domenech N., Rodríguez-Carreño M.P., Filgueira P., Alvarez B., Chamorro S., Domínguez J., Identification of porcine macrophages with monoclonal antibodies in formalin-fixed, paraffin-embedded tissues, Vet. Immunol. Immunopathol. (2003) 94:7781.

[14] Droemann D., Goldmann T., Branscheid D., Clark R., Dalhoff K., Zabel P., Vollmer E., TLR2 is expressed by alveolar epithelial cells type II and macrophages in human lung, Histochem. Cell Biol. (2003) 119:103108.

[15] Flo T.H., Halaas O., Torp S., Ryan L., Lien E., Dybdahl B., Sundan A., Espevik T., Differential expression of Toll-like receptor 2 in human cells, J. Leukoc. Biol. (2001) 69:474-481.

[16] Fusunyan R.D., Nanthakumar N.N., Baldeon M.E., Walker W.A., Evidence for an innate immune response in immature human intestine: Toll-like receptors on fetal enterocytes, Pediatr. Res. (2001) 49:589593.

[17] Gonzalez S., Mendoza C., Sánchez-Vizcaino J.M., Alonso F., Inhibitory effect of African swine 
fever virus on lectin-dependent swine lymphocyte proliferation, Vet. Immunol. Immunopathol. (1990) 26:71-80.

[18] Hertz C.J., Kierstscher S.M., Godowski P.J., Bouis D.A., Norgard M.V., Roth M.D., Modlin R.L., Microbial lipopeptides stimulate dendritic cell maturation via toll-like receptor 2, J. Immunol. (2001) 166:2444-2450.

[19] Hertz C.J., Wu Q., Porter E.M., Zhang Y.J., Weismuller K.H., Godowski P.J., Ganz T., Randell S.H., Modlin R.L., Activation of toll-like receptor 2 on human tracheobronchial epithelial cells induces the antimicrobial peptide beta-defensin-2, J. Immunol. (2003) 171:6820-6826.

[20] Iwasaki A., Medzhitov R., Toll-like receptor control of the adaptive immune responses, Nat. Immunol. (2004) 5:987-995.

[21] Janeway C.A. Jr, Medzhitov R., Innate immune recognition, Annu. Rev. Immunol. (2000) 20:197-216.

[22] Kagnoff M.F., Eckmann L., Epithelial cells as sensors for microbial infection, J. Clin. Invest. (1997) 100:6-10.

[23] Kohler G., Milstein C., Continuous cultures of fused cells secreting antibody of predefined specificity, Nature (1975) 256:495-497.

[24] Komai-Koma M., Jones L., Ogg G.S., Xu D., Liew F.Y., TLR2 is expressed on activated T cells as a costimulatory receptor, Proc. Natl. Acad. Sci. USA (2004) 101:3029-3034.

[25] Michelsen K.S., Aicher A., Mohaupt M., Hartung T., Dimmeler S., Kirschning C.J., Schumann R.R., The role of toll-like receptors (TLRs) in bacteriainduced maturation of murine dendritic cells (DCs): peptidoglycan and lipoteichoic acid are inducers of DC maturation and require TLR2, J. Biol. Chem. (2001) 276:25680-25686.

[26] Muneta Y., Uenishi H., Kikuma R., Yoshihara K., Shimoji Y., Yamamoto R., Hamashima N., Yokomizo Y., Mori Y., Porcine TLR2 and TLR6: identification and their involvement in Mycoplasma hyopneumoniae infection, J. Interferon Cytokine Res. (2003) 23:583590.

[27] Ochoa M.T., Legaspi A.J., Hatziris Z., Godowski P.J., Modlin R.L., Sieling P.A., Distribution of Toll-like receptor 1 and Toll-like receptor 2 in human lymphoid tissue, Immunology (2003) 108:10-15.

[28] Sabroe I., Jones E.C., Usher L.R., Whyte M.K., Dower S.K., Toll-like receptor (TLR) 2 and TLR4 in human peripheral blood granulocytes: a critical role for monocytes in leukocyte lipopolysaccharide responses, J. Immunol. (2002) 168:4701-4710.

[29] Schjetne K.W., Thompson K.M., Nielsen N., Flo T.H., Fleckestein B., Iversen J.G., Espevik T., Bogen
B., Link between innate and adaptive immunity: Tolllike receptor 2 internalises antigen for presentation to CD4+ T cells and could be an efficient vaccine target, J. Immunol. (2003) 171:32-36.

[30] Summerfield A, Guzylack-Piriou L, Schaub A, Carrasco C.P, Tache V, Charley B, McCullough K.C., Porcine peripheral blood dendritic cells and natural interferon-producing cells, Immunology (2003) 110:440-9.

[31] Takeda K., Akira S., Toll-like receptors in innate immunity, Int. Immunol. (2005) 17:1-14.

[32] Takeuchi O., Kawai T., Muhlradt P.F., Morr M., Radolf J.D., Zychlinsky A., Takeda K., Akira S., Discrimination of bacterial lipoproteins by toll-like receptor 6, Int. Immunol. (2001) 13:933-940.

[33] Takeuchi O., Sato S., Horiuchi T., Hoshino K., Takeda K., Dong Z., Modlin R.L., Akira S., Cutting edge: role of toll-like receptor 1 in mediating immune response to microbial lipoproteins, J. Immunol. (2002) 169:10-14.

[34] Thoma-Uszynski S., Kiertscher S.M., Ochoa M.T., Bouis D.A., Norgard M.V., Miyake K., Godowsky P.J., Roth M.D., Modlin R.L., Activation of toll-like receptor 2 on human dendritic cells triggers induction of IL-12, but not IL-10, J. Immunol. (2000) 165:3804-3810.

[35] Thono M., Kitazawa H., Shimosato T., Matsumoto M., Katoh S., Kawai Y, Saito T., A swine toll-like receptor 2 expressing transfectant as a potential primary screening system for immunobiotic microorganisms, FEMS Immunol. Med. Microbiol. (2005) 44: 283-288.

[36] Tohno M., Shimosato T., Kitazawa H., Katoh S., Iliev I.D., Kimura T., Kawai Y., Watanabe K., Aso H., Yamaguchi T., Saito T., Toll-like receptor 2 is expressed on the intestinal $\mathrm{M}$ cells in swine, Biochem. Biophys. Res. Commun. (2005) 330:547-554.

[37] Tohno M., Shimosato T., Moue M., Aso H., Watanabe K., Kawai Y., Yamaguchi T., Saito T., Kitazawa H., Toll-like receptor 2 and 9 are expressed and functional in gut-associated lymphoid tissues of presuckling newborn swine, Vet Res (2006) 37:791812.

[38] Visintin A., Mazzoni A., Spitzer J.H., Wyllie D.H., Dower S.K., Segal D.M. Regulation of Toll-like receptors in human monocyte and dendritic cells, J. Immunol. (2001) 166:249-255.

[39] Wolfs T.G., Buuman W.A., van Schadewijk A., de Vries B., Daemen M.A., Hiemstra P.S., van't Veer C., In vivo expression of Toll-like receptor 2 and 4 by renal epithelial cells: IFN-gamma and TNF alpha mediated up-regulation during inflammation, J. Immunol. (2002) 168:1286-1293. 